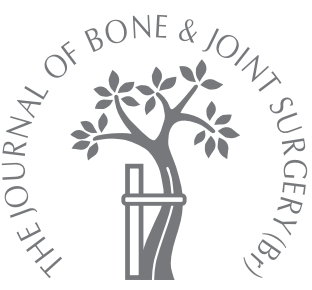

N. J. Goddard, H. A. Mann, C. A. Lee

From the Royal Free Hospital, London, United Kingdom

\title{
Total knee replacement in patients with end- stage haemophilic arthropathy
}

\author{
25-YEAR RESULTS
}

Haemophilia is an $\mathbf{x}$-linked inherited bleeding disorder which can cause severe arthropathy. We have reviewed the results of 70 primary total knee replacements (TKR) performed in 57 haemophilic patients between 1983 and 2007. The functional results were assessed using the Hospital for Special Surgery (HSS) knee scoring system and Kaplan-Meier survivorship analysis. Six patients died. HSS scores were available for 60 TKRs at a mean follow-up of 9.2 years (2 to 23); 57 (95\%) had good or excellent results. Deep infection was recorded in one patient. Kaplan-Meier analysis using infection and aseptic loosening as endpoints showed the survival rate at 20 years to be $\mathbf{9 4 . 0} \%$.

A reduction in infection, spontaneous haemarthrosis and improvement in the quality of life were noted to justify surgery in our series of patients with a mean age of 43 (25 to 70). We have found that using the latest techniques of continuous infusion of clotting Factor have significantly helped to reduce the complication rates and have achieved results which match those of the non-haemophilic population undergoing TKR.

Inherited bleeding disorders are most commonly characterised by the lack of clotting Factors. Haemophilia A and B are X-linked recessive disorders resulting from the lack of clotting Factors VIII and IX, respectively.

Patients with severe haemophilia, i.e. a Factor concentration of less than $1.0 \mathrm{IU} / \mathrm{dl}$, with an established joint which displays a tendency towards recurrent bleeding develop severe degenerative changes after repeated episodes of intra-articular bleeding. ${ }^{1,2}$ The severity of haemophilia is defined by a traditional classification $^{3}$ (Table I).

Iron has been proposed to be the agent responsible for inducing inflammation of the synovial membrane, leading to hypertrophy and hyperplasia. Iron induces the expression of various oncogenes leading to the proliferation of human synovial fibroblast cells. ${ }^{4}$ Ironloaded tissues have been shown, both in vitro and in vivo, to synthesise high levels of proinflammatory cytokines such as interleukin (IL)-6, IL-1 and tumour necrosis factor alpha. ${ }^{4}$

Macroscopically, the synovial membrane is thickened and nodular with friable synovial fronds projecting into the joint which is discoloured due to the deposition of haemosiderin. Over the central areas of cartilage there is deposition of a brown pigment suggestive of iron. The microscopic changes include synoviocyte hyperplasia with a marked angiomatous reaction and subintimal fibrosis. ${ }^{5}$ Hence there is a close link between the development of synovial hypertrophy, recurrent haemarthroses and progressive degradation of cartilage leading to haemophilic arthropathy.

Patients present with a wide range of clinical manifestations depending upon the severity of the condition. The knee is the most commonly involved joint and with the ankle and elbow account for almost $80 \%$ of the joints affected. In time a debilitating arthritis, haemophilic arthropathy, develops (Fig. 1).

Previous reports of total knee replacement (TKR) for end-stage haemophilic arthropathy have included only a small number of cases with relatively short follow-up. Poor results including deep sepsis, mechanical failure and technical difficulties with failure rates of up to $20 \%$ have been reported. ${ }^{6-14}$ A small number of studies have reported encouraging results, ${ }^{15-22}$ but the number of cases have been relatively small with a short period of follow-up.

Our aim therefore was to report our experience and the long-term results of primary TKR in patients with severe haemophilia over the last 25 years.

\section{Patients and Methods}

We reviewed the results of 70 primary TKRs in 57 haemophilic patients with severe haemophilia who had undergone TKR between 1983 
Table I. Details of the classification of the severity of haemophilia

\begin{tabular}{lll}
\hline Severity & $\begin{array}{l}\text { Clotting factor level } \\
\text { (\% activity/ (IU/mI)) }\end{array}$ & Bleeding episodes \\
\hline Severe & $1(<0.01)$ & Spontaneous joints and muscle \\
Moderate & 1 to $5(0.01$ to 0.05$)$ & Occasional/severe with trauma \\
Mild & 5 to $40(0.05$ to 0.40$)$ & Severe with major trauma or surgery \\
\hline
\end{tabular}

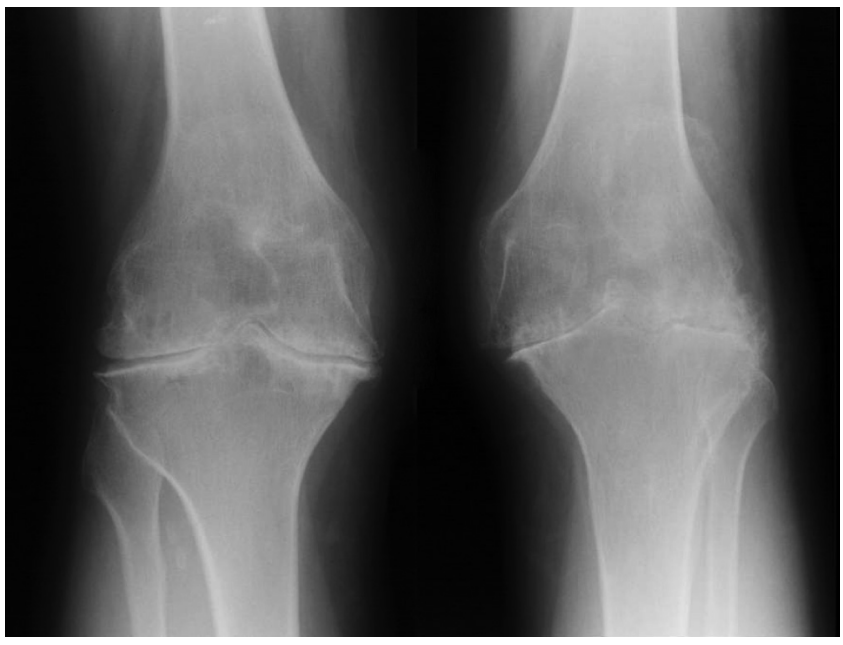

Fig. 1

Anteroposterior radiographs of end-stage bilateral haemophilic arthropathy.

and 2007. Ethical approval had been granted. Preoperatively, routine haematological and biochemical analysis had been performed. The pre-operative management consisted of assessment of the nature and severity of the bleeding disorder and the presence of inhibitors to coagulation Factors, hepatitis and HIV status.

Unilateral TKR was performed in 44 patients and a bilateral procedure in 13 of which seven were staged with two admissions, and six were sequential with one admission and one anaesthetic. Two of those undergoing unilateral TKR had a simultaneous contralateral total hip replacement for end-stage haemophilic arthropathy. The clinical details were recorded including the age, type and severity of the haemophilia and the HIV status and CD4 count at the time of surgery.

The mean age of the patients at the time of surgery was 43 years ( 25 to 70 ). Of the 57 patients, 41 had haemophilia A and 16 haemophilia B, 41 (72\%) were HIV-negative and $16(28 \%)$ HIV-positive at the initial operation. Two had inhibitors. A pre-operative CD4 count of $>200$ cells $/ \mathrm{mm}^{3}$ was used to determine inclusion for those patients who were HIV-positive. The mean pre-operative CD4 count was 380 cells $/ \mathrm{mm}^{3}$ (220 to 637 ) and the mean post-operative count 283 cells $/ \mathrm{mm}^{3}$ (235 to 551).

All patients without inhibitors received Factor VIII or IX replacement according to the department protocol. The
Table II. Details of the types of implant used

\begin{tabular}{lc}
\hline Prosthesis & Number \\
\hline Deane $^{*}$ & 7 \\
Insall-Burstein I (CR) $^{\dagger \ddagger}$ & 2 \\
Insall-Burstein II (CR) $^{\ddagger}$ & 10 \\
Miller-Galante I (CR) & 2 \\
AGC (CR)§ & 49 \\
Total & 70 \\
\hline * Deloro Surgical, Zimmer, Swindon, United Kingdom \\
† CR, cruciate retaining \\
‡ Zimmer, Warsaw, Indiana \\
§ Biomet Ltd, Swindon, United Kingdom
\end{tabular}

two patients with inhibitors received recombinant Factor VIIa concentrate. Pre-operatively, all patients had been given a bolus dose of clotting Factor in order to increase levels to $100 \%$. A continuous infusion of Factor VII, VIII or IX was then started at the induction of anaesthesia at a rate of $4 \mathrm{U} / \mathrm{kg} /$ hour (Factor VIII) and $6 \mathrm{U} / \mathrm{Kg} /$ hour (Factor IX). Continuous infusion was continued for seven days postoperatively, aiming for Factor levels of $100 \%$. This was followed by a daily bolus for a further seven days to maintain the levels at $100 \mathrm{U} / \mathrm{dl}$ and to allow post-operative rehabilitation without the risk of further bleeding from joints. After this prophylactic therapy was continued for up to eight weeks during the rehabilitation phase. All the patients received mechanical thromboprophylaxis with the wearing of compression stockings.

The operative procedure involved a standard mid-line incision and a medial parapatellar approach. Antibiotic prophylaxis (3rd generation Cetalosporin, 1 dose preoperatively, 2 post-operatively) was used in all the patients. The prostheses were cemented with antibiotic-loaded cement (Palacos R, Zimmer, Warsaw, Indiana). Six types of implant were used (Table II). All the bilateral sequential TKRs were performed using the same set of instruments for both. Tourniquets were applied to both thighs. Both limbs were prepared and draped in the usual manner. The tourniquets were then inflated sequentially.

The pre- and post-operative range of movement were assessed by the authors (NJG, HM) and physiotherapy specialists and complications after surgery were noted. The functional results were assessed using the Hospital for Special Surgery (HSS) knee scoring system both pre- and postoperatively. ${ }^{23}$ 


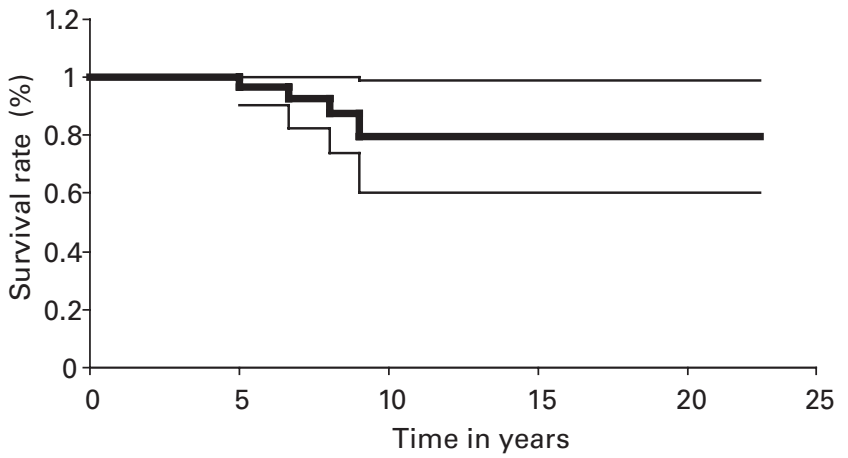

Fig. 2

Kaplan-Meier survivorship curve with removal of the component for any cause as the endpoint.

Statistical analysis. We used SAS 9.1 (SAS Institute Inc., Cary, North Carolina) software to assess the survival of the replacement at five, ten and 20 years. We defined failure as removal of a component for any reason, including infection and aseptic loosening. A p-value $\leq 0.05$ was deemed to be significant.

\section{Results}

Post-operatively, no patient was noted to seroconvert and no progression of HIV was recorded. All the patients were followed up for a mean of 9.2 years $(2.0$ to 23.0). Six patients (six knees) had died at the time of our study at a mean of 17.8 years (9.4 to 22.6) after surgery. All had acquired HIV from infected clotting Factor products and died from AIDS-related complications. There were postoperative complications in seven knees. Early complications included a superficial wound haematoma in two patients which responded to a simple washout.

Two patients had a DVT, and one of these had a pulmonary embolus. Both had haemophilia B and had undergone surgery in 1988 and 1989, respectively. It was during this period that Factor VIII and IX were of intermediate purity and the recombinant Factor concentrates were unavailable. Hence, during this phase of treatment more complications were seen in relation to the use of high-volume Factor replacement regimes. The patient with isolated ipsilateral below-knee DVT was treated conservatively. The other with a pulmonary embolus was initially treated by the addition of unfractionated heparin to the post-operative regime, which led to a successful resolution. Currently, there are no haemophilia treatment guidelines on this topic and no consensus statements from professionals or patient advocacy groups. One patient developed early post-operative neurapraxia of the ulnar nerve which resolved over the course of three months. A second developed a neurapraxia of the sciatic nerve after simultaneous bilateral TKR, which was thought to be secondary to release of the flexion contracture. The symptoms had resolved 18 weeks after surgery.

One patient had recurrent acute post-operative haemarthroses. Initially, these were treated conservatively with Fac-

$\begin{aligned} & \text { Table } \\
& \text { rates }\end{aligned}$
\begin{tabular}{lll} 
Year & Suplan-Meier & survival \\
\hline 1 & 100 & 100 \\
5 & 97 & 90 to 100 \\
10 & 80 & 60 to 98 \\
15 & 80 & 60 to 98 \\
20 & 80 & 60 to 98 \\
\hline
\end{tabular}
${ }^{*} \mathrm{Cl}$, confidence interval

tor replacement. However, when the patient failed to respond angiography revealed an aneurysm of the lateral superior genicular artery which responded well to embolisation. ${ }^{24}$

Deep infection was recorded in one patient who was HIV-positive. He presented with a dental abscess five years after TKR. After extraction of his tooth he developed haemarthroses and a painful swollen knee. A deep infection of Strep. Pyogenes was diagnosed. He underwent a successful two-stage revision procedure. The infection was confirmed to be secondary to the dental abscess. In total, six components were removed for aseptic loosening and one for deep infection. Of the six patients with aseptic loosening, four had their initial operation at our institution and two had previously been operated upon elsewhere.

The mean range of movement was $68^{\circ}\left(20^{\circ}\right.$ to $\left.130^{\circ}\right)$ pre-operatively and $79^{\circ}\left(20^{\circ}\right.$ to $\left.120^{\circ}\right)$ at the final followup. The mean flexion contracture was $9.6^{\circ}\left(0^{\circ}\right.$ to $\left.30^{\circ}\right)$ preoperatively and $4.7^{\circ}\left(0^{\circ}\right.$ to $\left.20^{\circ}\right)$ one year after surgery. Post-operative manipulation under anaesthesia was performed in 16 knees $(22.8 \%)$. Continuous passive movement was used in 52 knees $(74.3 \%)$. Patients with HIV were evaluated to assess their medical status and those with a CD4 count of $>200$ cells $/ \mathrm{mm}^{3}$ were considered to be suitable for TKR. ${ }^{9}$ There was no difference in the prevalence of infection in our patients with HIV compared with those without. No difference was noted in the complication rate between the 16 patients ( 17 knees) who were HIV-positive and the 41 (53 knees) who were HIVnegative.

The HSS scores were available for 49 patients (60 TKRs). The mean clinical score after surgery was 82 (70 to 95 ) and 46 (57 TKRs (95\%)) had a good or excellent result.

The five- and ten-year rates of survival of the TKRs with removal of a component for any cause were $98.0 \%$ and $89.0 \%$, respectively (Fig. 2, Table III). When removal of a component for aseptic loosening was the endpoint, the five- and ten-year survival rates were $98.0 \%$ and $80 \%$ respectively.

\section{Discussion}

An operation in a patient with haemophilia is a complex procedure. Most of our patients were young men, whose quality of life was considerably affected by the destruction of a single joint. Our major objective in total joint 
replacement surgery was to reduce the level of pain in the affected joint.

The long-term results showed improved functional scores, good prosthetic survival and above all significantly low infection rates (Wilcoxon-Rank test, $\mathrm{p}=0.038$ ). They do not appear to be comparable with those of other studies, in which failure and complication rates were significantly higher, the number of cases relatively small and the follow-up rather short which meant that no definite conclusions could be reached. ${ }^{6-22}$ Infection and aseptic loosening appeared to be the main complication with the overall rate of survival being less favourable than that in the non-haemophilic population in most of these studies. In our study infection has not been a common problem. The results appear to be comparable to those of TKR in the non-haemophilic population ${ }^{25-30}$ with a prevalence of infection of under $2 \%$ and long-term survival of $95.0 \%$ at 20 years.

In a multicentre study, Ragni et $\mathrm{al}^{9}$ reported the rate of post-operative infection in HIV-positive patients with haemophilia with CD4 counts $<200$ cells $/ \mathrm{mm}^{3}$. An incidence of infection of $30 \%$ was noted in contrast to that of $1 \%$ to $2 \%$ in the non-haemophilic population. They concluded that when offering any surgery to HIV-infected patients with a CD4 count $<200$ cells $/ \mathrm{mm}^{3}$, analysis of the risk-benefit ratio should be made. Early, vigorous treatment should be instituted for suspected infection, antibiotic prophylaxis considered for invasive procedures and surgical intervention individualised, based on the balance of risks and benefits.

However, data from Birch et $\mathrm{al}^{31}$ were more encouraging, reporting no evidence to suggest that TKR had any adverse effects on the rate of decline in the CD4 count, the onset of AIDS or the rate of mortality. In our study we found that the rate of infection was similar in both HIVpositive and HIV-negative patients, comparing favourably with previous reports. ${ }^{12,14}$

The use of continuous infusion Factor replacement during the pre-, peri- and early post-operative phases may account for the improved results. First, compared with bolus dose Factor replacement, this regime avoids the peakand-trough levels of the clotting Factor. Hence, it is more likely that a consistent level of Factor will prevent any blood being present at the cancellous bone interface, which is crucial to fixation of the implant. Maintenance of a clear cement-bone interface allows for improved micro-locking of cement into cancellous bone thereby reducing the stresses which occur at the cement-bone interface and preventing early failure.

Despite the challenges posed in this subpopulation of patients, our study indicated improved rates of survival of TKR in haemophilic patients. With infection as an endpoint, the survival rate at 20 years in our patients was $97.0 \%$. We work in close conjunction with our haematology colleagues to establish the Factor replacement regime, tailored to patients undergoing orthopaedic surgery. Specialist haemophilia nurses play a key role in monitoring patients on the orthopaedic ward during the pre- and post- operative stages. Our haemophilia department also employs a specialist dedicated musculoskeletal physiotherapist. The protocol of treatment allows early rehabilitation in our patients with the reduced risk of wound complications. There are monthly multidisciplinary musculoskeletal clinics in the haemophilia department, at which new and follow-up patients are reviewed allowing all aspects of patient management to be discussed by the orthopaedic and the haemophilia teams.

It is important to educate patients regarding meticulous antisepsis during self-infusion. It has been proposed that typical skin micro-organisms may be responsible for most of the observed infections as a result of the self-administration of Factor concentrates. ${ }^{11}$ Other suggestions include regular medical review and the immediate reporting of any signs of infection. The regime includes the use of prophylactic antibiotics before any dental work and any other procedures with a potential for contamination. The use of short-term prophylactic antibiotics before self-infusion should also be considered. ${ }^{11}$

For haemophilic patients in the developing world there is accumulating evidence that better prophylaxis in childhood and adolescence is leading to a marked reduction in arthropathy. ${ }^{22}$ It is to be hoped that the need for operative intervention will also diminish. Despite this, the ankle joint seems to be a challenge for the future. Ultimately, of course gene therapy may cure the disease. Thus before embarking on a potentially dangerous procedure the orthopaedic surgeon should consider the risks and benefits carefully, taking into account the patient's age, ambitions, life expectancy and immunological status. The patient should be managed in a dedicated haemophilia centre where a comprehensive team approach can be provided. It would seem that joint replacement surgery should be the treatment of choice in haemophilic patients with severe arthropathy. There can be little doubt that a successful arthroplasty provides considerable benefits in most haemophilic patients, with marked relief from pain and improvement in function. However, the increased risk of infection and non-infective complications remains a cause for concern.

No benefits in any form have been received or will be received from a commercial party related directly or indirectly to the subject of this article.

\section{References}

1. Arnold WD, Hilgartner MW. Hemophilic arthropathy: current concepts of pathogenesis and management. J Bone Joint Surg [Am] 1977;59-A:287-305.

2. Stein H, Duthie RB. The pathogenesis of chronic haemophilic arthropathy. J Bone Joint Surg [Br] 1981;63-B:601-9.

3. White GC 2nd, Rosendaal F, Aledort LM, et al. Definitions in hemophilia: recommendation of the scientific subcommittee on factor VIII and factor IX of the scientific and standardization committee of the International Society on Thrombosis and Haemostasis. Thromb Haemost 2001;85:560.

4. Hakobyan N, Kazarian T, Jabbar AA, Jabbar KJ, Valentino LA. Pathobiology of hemophilic synovitis I: overexpression of mdm2 oncogene. Blood 2004;104:2060-4.

5. Goddard NJ, Mann H. Diagnosis of haemophilic synovitis. Haemophilia 2007;13(Suppl 3):14-19.

6. Figgie MP, Goldberg VM, Figgie HE 3rd, Heiple KG, Sobel M. Total knee arthroplasty for the treatment of chronic hemophilic arthropathy. Clin Orthop 1989;248:98107. 
7. Thomason HC 3rd, Wilson FC, Lachiewicz PF, Kelley SS. Knee arthroplasty in hemophilic arthropathy. Clin Orthop 1999;360:169-73.

8. Lachiewicz PF, Inglis $\mathbf{A E}$, Insall JN, et al. Total knee arthroplasty in hemophilia. J Bone Joint Surg [Am] 1985;67-A:1361-6.

9. Ragni MV, Crossett LS, Herndon JH. Postoperative infection following orthopaedic surgery in human immunodeficiency virus-related hemophiliacs with CD4 counts < or $=200 / \mathrm{mm} 3$. J Arthroplasty 1995;10:716-21.

10. Vastel L, Courpied JP, Sultan Y, Kerboull M. Knee replacement arthroplasty in hemophilia: results, complications and predictive elements of their occurrence. Rev Chir Orthop Reparatrice Appar Mot 1999;85:458-65 (in French).

11. Silva M, Luck JV Jr. Long-term results of primary total knee replacement in patients with hemophilia. J Bone Joint Surg [Am] 2005;87-A:85-91.

12. Norian JM, Ries MD, Karp S, Hambleton J. Total knee arthroplasty in hemophilic arthropathy. J Bone Joint Surg [Am] 2002;84-A:1138-41.

13. Powell DL, Whitener CJ, Dye CE, et al. Knee and hip arthroplasty infection rates in persons with haemophilia: a 27 year single center experience during the HIV epidemic. Haemophilia 2005;11:233-9.

14. Hicks JL, Ribbans WJ, Buzzard B, et al. Infected joint replacements in HIV-positive patients with haemophilia. J Bone Joint Surg [Br] 2001;83-B:1050-4.

15. Teigland JC, Tjønnfjord GE, Evensen SA, Charania B. Knee arthroplasty in hemophilia: 5-12 year follow-up of 15 patients. Acta Orthop Scand 1993:64:153-6.

16. Marmor L. Total knee replacement in haemophilia. Clin Orthop 1977;125:192-5

17. Goldberg VM, Heiple KG, Ratnoff OD, Kurczynski E, Arvan G. Total knee arthroplasty in classic hemophilia. J Bone Joint Surg [Am] 1981;63-A:695-701.

18. Small M, Steven MM, Freeman PA, et al. Total knee arthroplasty in haemophilic arthritis. J Bone Joint Surg [Br] 1983;65-B:163-5.

19. Magone JB, Dennis DA, Weis LD. Total knee arthroplasty in chronic hemophilic arthropathy. Orthopedics 1986;9:653-7.
20. Karthaus RP, Novakova IR. Total knee replacment in haemophilic arthropathy. J Bone Joint Surg [Br] 1988;70-B:382-5.

21. Luck JV Jr, Kasper CK. Surgical management of advanced hemophilic arthropathy: an overview of 20 years' experience. Clin Orthop 1989;242:60-82.

22. Cohen I, Heim M, Martinowitz U, Chechick A. Orthopaedic outcome of total knee replacement in haemophilia A. Haemophilia 2000;6:104-9.

23. Insall JN, Ranawat CS, Aglietti P, Shine J. A comparison of four models of total knee-replacement prostheses. J Bone Joint Surg [Am] 1976;58-A:754-65.

24. Mann HA, Goddard NJ, Lee CA, Brown SA. Periarticular aneurysm following total knee replacement in hemophilic arthropathy: a case report. J Bone Joint Surg [Am] 2003;85-A:2437-40.

25. Aglietti P, Buzzi R, De Felice R, Giron F. The Insall-Burstein total knee replacement in osteoarthritis: a 10-year minimum follow-up. J Arthroplasty 1999;14:560-5.

26. Ayers DC, Dennis DA, Johanson NA, Pellegrini VD Jr. Instructional course lectures, The American Academy of Orthopedic Surgeons: common complications of total knee arthroplasty. J Bone Joint Surg [Am] 1997;79-A:278-311.

27. Bengtson S, Knutson K. The infected knee arthroplasty: a 6-year follow-up of 357 cases. Acta Orthop Scand 1991;62:301-11.

28. Peersman G, Laskin R, Davis J, Peterson $\mathbf{M}$. Infection in total knee replacement: a retrospective review of 6489 total knee replacements. Clin Orthop 2001;392:15-23.

29. Wilson MG, Kelley K, Thornhill TS. Infection as a complication of total kneereplacement arthroplasty: risk factors and treatment in sixty-seven cases. J Bone Joint Surg [Am] 1990;72-A:878-83.

30. Ritter MA. The anatomical graduated component total knee replacement: a long-term, evaluation with 20-year survival analysis. J Bone Joint Surg [Br] 2009;91-B:745-9.

31. Birch NC, Ribbans WJ, Goldman E, Lee CA. Knee replacement in haemophilia. J Bone Joint Surg [Br] 1994;76-B:165-6. 